\title{
Molecular cloning, expression, IgE binding activities and in silico epitope prediction of Per a 9 allergens of the American cockroach
}

\author{
HAIWEI YANG ${ }^{1,3^{*}}$, HAO CHEN $^{2 *}$, MIN JIN $^{2 *}$, HUA XIE $^{4}$, SHAOHENG HE $^{1}$ and JI-FU WEI ${ }^{2}$ \\ ${ }^{1}$ Allergy and Clinical Immunology Research Centre, The First Affiliated Hospital of Liaoning Medical University, Jinzhou, \\ Liaoning 121001; ${ }^{2}$ Research Division of Clinical Pharmacology, and ${ }^{3}$ Department of Urology, The First Affiliated Hospital \\ of Nanjing Medical University, Nanjing, Jiangsu 210029; ${ }^{4}$ Department of Respiratory Medicine, General Hospital \\ of Shenyang Military Region, PLA Cancer Center, Shenyang, Liaoning 110840, P.R. China
}

Received October 10, 2015; Accepted October 19, 2016

DOI: $10.3892 /$ ijmm.2016.2793

\begin{abstract}
Per a 9 is a major allergen of the American cockroach $(\mathrm{CR})$, which has been recognized as an important cause of imunoglobulin E-mediated type I hypersensitivity worldwide. However, it is not neasy to obtain a substantial quantity of this allergen for use in functional studies. In the present study, the Per a 9 gene was cloned and expressed in Escherichia coli (E. coli) systems. It was found that $13 / 16(81.3 \%)$ of the sera from patients with allergies caused by the American CR reacted to Per a 9, as assessed by enzyme-linked immunosorbent assay, confirming that Per a 9 is a major allergen of CR. The induction of the expression of CD63 and CCR3 in passively sensitized basophils (from sera of patients with allergies caused by the American CR) by approximately 4.2-fold indicated that recombinant Per a 9 was functionally active. Three immunoinformatics tools, including the DNASTAR Protean system, Bioinformatics Predicted Antigenic Peptides (BPAP) system and the BepiPred 1.0 server were used to predict the potential B cell epitopes, while Net-MHCIIpan-2.0 and NetMHCII-2.2 were used to predict the T cell epitopes of Per a 9. As a result, we predicted 11 peptides (23-28, 39-46, 58-64, 91-118, 131-136, 145-154, 159-165, 176-183, 290-299, 309-320 and 338-344) as potential B cell linear epitopes. In $\mathrm{T}$ cell prediction, the Per a 9 allergen was predicted to have 5 potential T cell epitope sequences, 119-127, 194-202, 210-218,
\end{abstract}

Correspondence to: Professor Shaoheng He, Allergy and Clinical Immunology Research Centre, The First Affiliated Hospital of Liaoning Medical University, Section 5, 2 Renmin Street, Guta, Jinzhou, Liaoning 121001, P.R. China

E-mail: shoahenghe@hotmail.com

Professor Ji-Fu Wei, Research Division of Clinical Pharmacology, The First Affiliated Hospital, Nanjing Medical University, 300 Guangzhou Road, 210029 Nanjing, P.R. China

E-mail: weijifu@hotmail.com

${ }^{*}$ Contributed equally

Key words: cockroach, allergen, Per a 9, epitopes, Escherichia coli, imunoglobulin E
239-250 and 279-290. The findings of our study may prove to be useful in the development of peptide-based vaccines to combat CR-induced allergies.

\section{Introduction}

Cockroach (CR) allergies have been recognized as an important cuase of imunoglobulin E (IgE)-mediated type I hypersensitivity since 1964 (1). In a previous study, it was found that $44 \%$ of 755 allergic patients who were treated at the allergy clinics in New York had positive reactions to CR extract in the skin prick test (SPT), and $13 \%$ of those subjects were allergic to CR alone (1). German CR (Blattella germanica; Bla g), American CR [Periplaneta americana (P. americana); Per a] and smoky brown CR (Periplaneta fuliginosa) are the dominant indoor CR species which cause allergies among populations worldwide (2). In China, a total of $25.7 \%$ of patients with allergies are found to be positive for American CR allergens and $18.7 \%$ are found to be positive for German CR allergens by the SPT (3).

There are $22 \mathrm{IgE}$ binding components in P. americana, including the proteins of $23,28,35,38,40,49,72,78$ and $97 \mathrm{kDa}$ as major allergens (4), but only a few of these allergens namely, Per a 1 (5), Per a 2 (previousy known as Cr PI) (6), Per a $3(7)$, Per a $4(8)$, Per a $5(9)$, Per a $6(10)$, Per a 7 (11), Per a 9 (previousy known as Periplaneta americana arginine kinase) (12) and Per a 10 (13) have been characterized. Per a 9 is an arginine kinase, purified from American CR extract by monoclonal antibody based-affinity chromatography reacted with IgE in sera of all CR allergic Thai patients (12). Attempts to isolate Per a 9 from the American CR extract have been extremely laborious and have resulted in low yields. To day, only 3 groups of researchers have submitted these allergen genes (AY563004.1, GU301882.1 and EU429466) in GenBank. The availability of the sequence makes it possible to produce recombinant Per a 9 in large amounts to study both its physiologic role and its implications in allergic reactions.

CR immunotherapy is uncommonly used and reports on its effectiveness are very limited $(14,15)$. The elucidation of $\mathrm{B}$ and $\mathrm{T}$ cell epitopes of allergens broaden our understanding of the structure-function relationship and predict the basis of cross-reactivity. The cross-reactive epitopes may be useful in reducing the number of allergens without compromising the 
efficacy of therapy (16). B cell epitopes can be applied in the diagnosis, therapy and development of effective vaccines for immunotherapy. They can be identified by a number of methods, particularly computational tools, which provide a promising and rapid alternative. The predicted $\mathrm{B}$ cell epitopes may be modified to reduce the allergenicity of an allergen (17). T cell epitopes have been successfully identified based on computer simulation over the past decade. Extracellular peptides have to bind to major histocompatibility complex (MHC) class II to stimulate $\mathrm{T}$ lymphocyte responses. Thus, $\mathrm{T}$ cell epitopes have been predicted indirectly by the identification of MHC-binding molecules (18). In the present study, we firstly cloned and expressed the American CR major allergen, Per a 9, and subseqently identified the B and T cell epitopes of the Per a 9 allergen using an in silico approach. Our findings provide evidence of their potential use in the development of peptidebased vaccines for combating CR allergies.

\section{Materials and methods}

Ethics statement. The study protocol was approved by the Ethics Committee of the First Affiliated Hospital of Nanjing Medical University, Nanjing, China. Written informed consent for the use of blood samples was obtained from all participants prior to study entry according to the declaration of Helsinki.

Patients and samples. A total of 16 patients with allergic rhinitis with positive SPT results (allergens were supplied by ALK-Abelló, Inc., Hørsholm, Denmark) and with positive serum IgE test results to American CR extract [by using ImmunoCAP assay (Pharmacia Diagnostics AB, Uppsala, Sweden)], and 6 healthy controls (HC) were recruited in this study. Serum (4 ml) from peripheral venous blood was collected from each patient and the healthy controls for western blot analysis.

Cloning of cDNA encoding the full length of Per a 9 gene. Total RNA was isolated from adult female CRs reared at our institute using TRIzol reagent (Invitrogen, Carlsbad, CA, USA). Total RNA was quantified by measuring the absorbance ratios at $260 / 280 \mathrm{~nm}$. cDNA was prepared by reverse transcriptase using a commercial RNA-PCR kit according to the manufacturer's instructions (Takara Biotech Co., Ltd., Dalian, China). For each reaction, $1 \mu \mathrm{g}$ of total RNA was reverse transcribed using oligo-d(T). cDNA encoding Per a 9 was amplified by PCR using primers based on the no-coding sequence of the Per a 9 gene (AY563004.1; forward, 5'-TACA GCAAGTGGGACAGCAG-3' and reverse, 5'-ATATGGGCAT CAAAGATATA- $3^{\prime}$ ). The PCR conditions were $95^{\circ} \mathrm{C} / 5 \mathrm{~min}$ ( 1 cycle), $95^{\circ} \mathrm{C} / 1 \mathrm{~min}, 55^{\circ} \mathrm{C} / 1 \mathrm{~min}$ and $72^{\circ} \mathrm{C} / 1 \mathrm{~min}$ ( 30 cycles), and $72^{\circ} \mathrm{C} / 5 \mathrm{~min}$ (1 cycle). The purified PCR product was cloned into the pMD18-T vector (Takara Biotech Co., Ltd.), before being transformed into Escherichia coli (E. coli) strain DH5a. The inserts were sequenced on an ABI Prism 377 DNA sequencer (Applied Biosystems, Foster City, CA, USA). DNA sequence data were translated to amino acid sequence using the Show Translation tool in the SMS software package (http:// www.bioinformatics.org/SMS/).

Expression and purification of Per a 9 in E. coli. The Per a 9 gene was subcloned into the pET15b vector (Novagen, Madison,
WI, USA) using the NdeI and BamHI sites and verified by DNA sequencing. The recombinant pET15b-Per a 9 plasmid was transformed into the ArcticExpress ${ }^{\mathrm{TM}}$ (DE3) RP host strain. A colony of the selected transformed ArcticExpress ${ }^{\mathrm{TM}}$ (DE3) RP E. coli on an overnight LB-ampicillin agar plate was inoculated into $5 \mathrm{ml}$ of LB-ampicillin broth, and incubated at 15,25 or $37^{\circ} \mathrm{C}$, respectively overnight. One milliliter of the culture was inoculated into $50 \mathrm{ml}$ of fresh LB-ampicillin broth and incubated at $37^{\circ} \mathrm{C}$ with shaking at $250 \mathrm{rpm}$ until the optical density (OD) at $A_{600 \mathrm{~nm}}$ reached 0.6 . Subsequently, IPTG was added to a final concentration of $1 \mathrm{mM}$ and the culture was incubated for a further $4 \mathrm{~h}$. The bacterial cells were harvested by centrifugation at $4,000 \times \mathrm{g}$ at $4^{\circ} \mathrm{C}$ for $20 \mathrm{~min}$, and were lysed in lysis buffer by sonication at $20 \mathrm{kHz}, 2 \mathrm{~min}$ pulse-on, 3 min pulse-off. Cell debris was removed by centrifugation at $12,000 \mathrm{x} \mathrm{g}$ at $4^{\circ} \mathrm{C}$ for $20 \mathrm{~min}$. The supernatant was loaded on a Nickel column (Genscript, Nanjing, China), washed with running buffer containing $50 \mathrm{mM}$ Tris- $\mathrm{HCl}, 300 \mathrm{mM} \mathrm{NaCl}$ and $5 \%$ glycerol (pH 8.0), and eluted with elution buffer containing $50 \mathrm{mM}$ Tris- $\mathrm{HCl}, 300 \mathrm{mM} \mathrm{NaCl}, 50$ and $250 \mathrm{mM}$ imidazole and 5\% glycerol ( $\mathrm{pH} \mathrm{8.0).} \mathrm{The} \mathrm{eluted} \mathrm{fractions} \mathrm{washed} \mathrm{with}$ $250 \mathrm{mM}$ imidazole were obtained and identified as Per a 9.

Immunoreactivity of human sera with recombinant Per a 9. A 96-well plate was coated with purified recombinant Per a 9 at $10 \mu \mathrm{g} / \mathrm{ml}$ in carbonate-bicarbonate buffer $(0.05 \mathrm{M}, \mathrm{pH}$ 9.6) overnight at $4^{\circ} \mathrm{C}, 100 \mu \mathrm{l} /$ well. Human serum samples [1:20 dilution in phosphate-buffered saline (PBS)-Tween-20 with 2\% BSA] were then added to the plates for $2 \mathrm{~h}$ at room temperature. Following IgE binding, the plates were incubated with horseradish peroxidase-labeled goat anti-human IgE (1:2,500 dilution) (KPL, Inc., Gaithersburg, MD, USA), and the color was developed with tetramethylbenzidine peroxidase substrate. The plates were read on a microplate reader (Eon; BioTek, Winooski, Vermont, USA) at an absorbance of $405 \mathrm{~nm}$. The cut-off of the enzyme-linked immunosorbent assay (ELISA) was calculated as the mean of the negative controls plus 2 standard deviations (SDs).

Western blot analysis of IgE reactivity. Immunoblots for the detection of serum specific IgE were performed using recombinant Per a 9 as previously described $(19,20)$. Recombinant Per a $9(5 \mu \mathrm{g})$ was added to a sodium dodecyl sulfate-polyacrylamide gel electrophoresis (SDS-PAGE) (gel concentration of $15 \%$ ) under reducing conditions and then transferred onto nitrocellulose membranes. The nitrocellulose membranes were incubated with the sera of the patients with American CR allergies (1:5 to 1:20 in PBS-Tween-20 with 1\% BSA, $10 \%$ normal goat serum) for $90 \mathrm{~min}$. Following rinsing with PBS, the membranes were incubated with peroxidase-labeled anti-human IgE monoclonal antibody. The positive protein bands were visualized by incubating the membranes with tetramethylbenzidine peroxidase substrate. Sera from 2 non-atopic subjects were used as negative controls.

Basophil activation test. The expression of CD63 and CCR 3 on the basophil surface is considered as an indicator of basophil activation $(21,22)$. Briefly, peripheral blood mononucleated cells (PBMCs) from $20 \mathrm{ml}$ blood donated by 4 healthy volunteers were separated by Ficoll-Paque density gradient, and treated with $10 \mathrm{ml} \mathrm{LS}$ (a solution containing $1.3 \mathrm{M} \mathrm{NaCl}$, 
$0.005 \mathrm{M} \mathrm{KCl}$ and 0.01 lactic acid, $\mathrm{pH} 3.9)$ for 2 min at $8^{\circ} \mathrm{C}$. Following neutralization with $12 \%$ Tris ( $\mathrm{pH} 10.9)$, non-specific IgE on the basophils was stripped off and the cells were passively sensitized with the sera of patients with American $\mathrm{CR}$ allergies or the healthy controls $(n=4,1$ in 10 dilution, $2 \mathrm{~h}$ at $37^{\circ} \mathrm{C}$ ) (same patients and controls as mentioned above) as previously described (22). The cells were then challenged with Per a $9(1.0 \mu \mathrm{g} / \mathrm{ml})$ for $15 \mathrm{~min}$ at $37^{\circ} \mathrm{C}$. A goat anti-human IgE antibody (Serotec, Kidlington, UK) was used as a positive control. CCR3-PE-labeled antibody (85-12-1939-42; eBioscience Inc., San Diego, CA, USA) and anti-human CD63-FITC antibody (HH-MHCD63014; Invitrogen) were added to the cells for $15 \mathrm{~min}$ at $37^{\circ} \mathrm{C}$. Flow cytometric analysis of surface markers was performed at $488 \mathrm{~nm}$ on a FACSAria flow cytometer (Becton-Dickinson, Franklin Lakes, NJ, USA) and analyzed by FACSDiva software.

Sequence retrieval and phylogenetic analysis. The complete amino acid sequence of the cloned Per a 9 gene was used as query to search for homologous sequences through the SwissProt/TrEMBL (Uniprot; http://www.uniprot.org/) and tBLASTn in NCBI (blast.ncbi.nlm.nih.gov/Blast.cgi) (10,23-25). The phylogenetic tree was obtained by using the maximum-likelihood (ML) method on the basis of the JTT amino acid sequence distance implemented in MEGA 5.1, and the reliability was evaluated by the bootstrap method with 1,000 replications (24-32).

Physiochemical analysis and post-translational patterns and motifs. Physiochemical analysis, including molecular weight, theoretical pI, amino acid composition, instability index, aliphatic index and the grand average of hydropathicity (GRAVY) of Per a 9 was performed using the ProtParam tool (http://web. expasy.org/protparam/), as previously described (33). The Per a 9 characteristic pattern was examined for the original sequence and further analysis was performed to highlight the presence of functional motifs using the Prosite database (http:// prosite.expasy.org/), as previously described (34).

Secondary structure prediction. Per a 9 secondary structural elements recognition was assessed by PSIPRED (bioinf. cs.ucl.ac.uk/psipred), which threads sequence segments through Protein Data Bank (PDB) library (http://www.pdb. org/) to identify conserved substructures (35). Furthermore, the secondary structure elements were also identified and compared with the results obtained with NetSurfP ver. 1.1 (www.cbs.dtu.dk) (36).

Homology modeling and validation. The Per a 9 protein sequence was searched for homology in the PDB (http://www. rcsb.org/). In addition, the homologous templates suitable for Per a 9 were selected using the PSI-BLAST server (http:// blast.ncbi.nlm.nih.gov/Blast.cgi) in the NCBI and Swiss-model server (http://swissmodel.expasy.org/). The best templates were retrieved from the results of PSI-BLAST and used for homology modeling. The Der f 25 modeled protein structure was built through Alignment Mode in SWISS-MODEL (http://swissmodel.expasy.org/) using the complete amino acid sequence. An initial structural model was generated and checked for recognition of errors in 3D structure by PROCHECK (37), ERRAT (verification of protein struc- tures: patterns of nonbonded atomic interactions) $(33,38)$ and VERIFY_3D (a method to identify protein sequences that fold into a known three-dimensional structure. Assessment of protein models with three-dimensional profiles) programs in Structural Analysis and Verification Server (http://nihserver. mbi.ucla.edu/SAVES/) $(33,38)$.

In silico prediction of $B$ cell epitopes. Three immunoinformatics tools, including the DNASTAR Protean system (39), Bioinformatics Predicted Antigenic Peptides (BPAP) system (http://imed.med.ucm.es/Tools/antigenic.pl) and the BepiPred 1.0 server (http://www.cbs.dtu.dk/services/ BepiPred/) were used to predict the B cell epitopes of Per a 9, as previously described (40). The ultimate consensus epitope results were obtained by combining the results of the three tools together with a previously published method (41). If the results of all 3 methods were non-epitope, then the consensus result was $0 \%$ epitope. Similarly, if the predicted results had only one or no non-epitope, the consensus result was 67 or $100 \%$ epitope, respectively. Finally, the regions whose consensus epitope result was 67 or $100 \%$ were selected as the final potential epitope regions. In the DNAStar Protean system, 4 properties (hydrophilicity, flexibility, accessibility and antigenicity) of the amino acid sequence were selected as parameters for epitope prediction. The peptide regions with good hydrophilicity, high flexibility, surface accessibility and high antigenic index were selected as candidate epitopes for further investigation. The BPAP system and BepiPred 1.0 server only need the amino acid sequence and provide more straightforward results, which combined with the physicochemical properties of amino acids such as hydrophilicity, flexibility, accessibility, turns and exposed surface (42).

In silico prediction of $T$ cell epitopes. $\mathrm{T}$ cell epitopes are principally predicted indirectly by identifying the binding of peptide fragments to the MHC complexes. However, the binding grooves of MCH-II molecules are open at both ends allowing various lengths of peptides to bind. On the other hand, the same MHC molecule can accommodate a variety of binding sequences. These two properties make the development of accurate predictive algorithms for MHC-class II binding complex. For HLA-DR-based T cell epitope prediction, the artificial neural network-based alignment (NN-align) method NetMHCIIpan-3.0 (http://www. cbs.dtu.dk/services/NetMHCIIpan/) was applied (43). For HLA-DQ alleles, NetMHCII-2.2 (http://www.cbs.dtu. $\mathrm{dk} /$ services/NetMHCII/) was used (44). Although HLA-DQ provides limited binding-affinity data, it was recently reported to provide the optimal performance in predicting this locus (33). The binding significance of each peptide to the given MHC molecule is based on the estimated strength of binding exhibited by a predicted nested core peptide at a set threshold level. For HLA-DR-based T cell epitope prediction, HLA-DR 101, HLA-DR 301, HLA-DR 401 and HLA-DR 501 were used. The ultimate HLA-DR-based T cell epitope results were obtained by combining those 4 results together and if 3 of these were shown to be epitope, the consensus result was then considered epitope. This method was also used in HLA-DQ-based T cell epitope prediction. For HLA-DQ-based T cell epitope prediction, only HLA-DQA10501-DQB10201, 


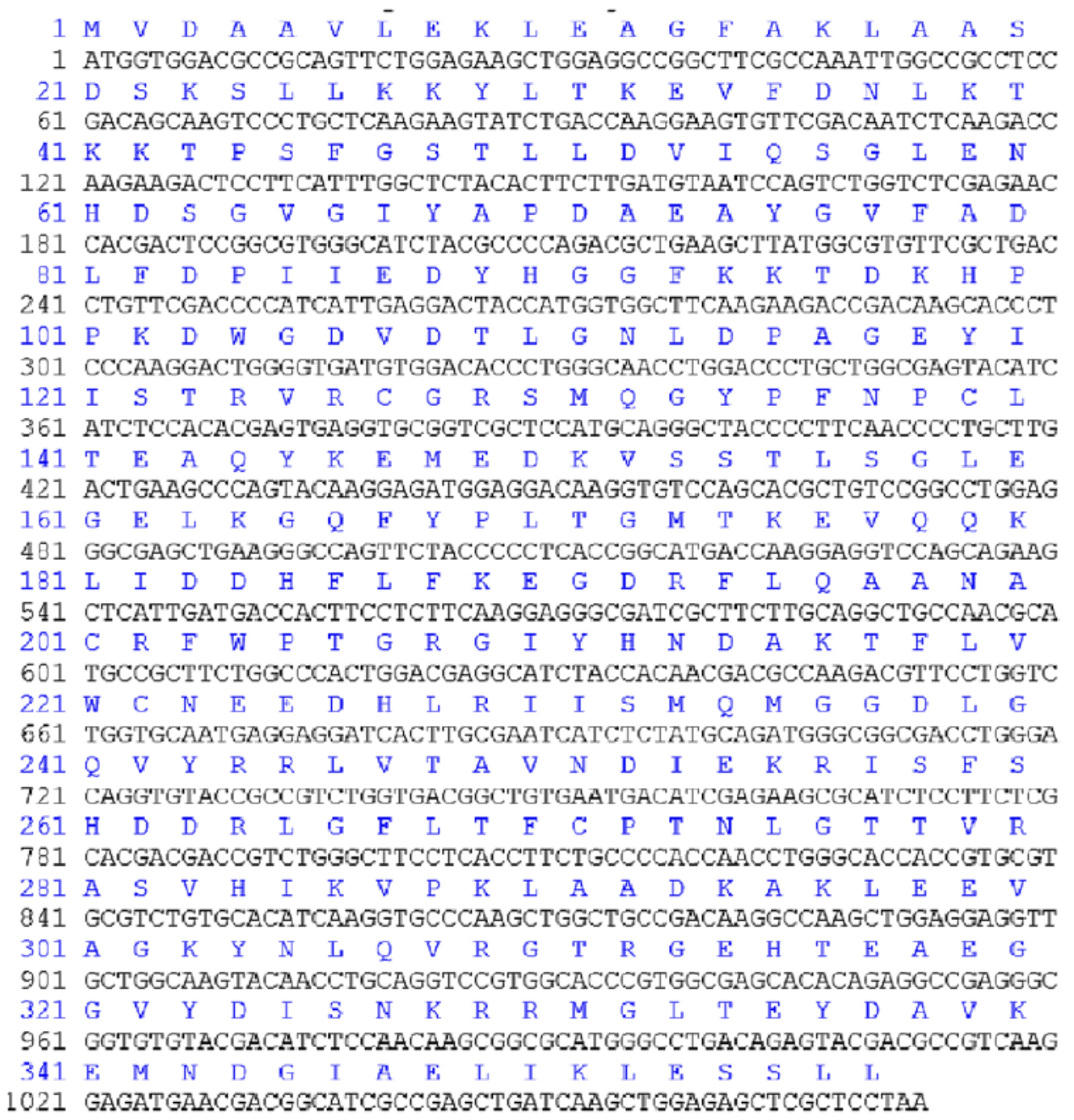

Figure 1. cDNA sequence encoding Per a 9 and the deduced amino acid sequence. The first 3 bases ATG represent the start code. The last 3 bases indicate the stop codon.

HLA-DQA10301-DQB10302, HLA-DQA10401-DQB10402 and HLA-DQA10102-DQB10602 were used. As a result, the ultimate consensus epitope results were obtained by combining the results of the HLA-DR-based T cell epitope and HLA-DQ-based T cell epitope. B cell and T cell epitopes identified by computational tools were mapped onto linear sequence and on the 3 dimensional model of Per a 9 in order to determine their position and secondary structure elements involved.

Statistical analysis. Data are expressed as the means \pm SE for the indicated number of independently performed duplicated experiments. Statistical significance between means was analyzed by one-way ANOVA or the Student's t-test utilizing the SPSS 13.0 version. A value of $\mathrm{P}<0.05$ was considered to indicate a statistically significant difference.

\section{Results}

Cloning of cDNA encoding full length Per a 9 sequence. cDNA encoding Per a 9 was amplified by PCR using primers based on the no-coding sequence of Per a 9 gene. It is a 1,074 bp gene and encodes a 356 amino acid protein (Fig. 1). The sequence homology with the published one (Accession no. AY563004) was $99 \%(353 / 356)$ at the protein level.

Expression and purification of Per a 9 in E.coli. The Per a 9 gene was subcloned into the pET15b vector and transformed into the ArcticExpress $^{\mathrm{TM}}$ (DE3) RP host strain. Per a 9 was expressed at 15,25 or $37^{\circ} \mathrm{C}$ following induction. Since Per a 9 was expressed in a soluble form in the supernatant at $15^{\circ} \mathrm{C}$ (Fig. 2A), the condition of $1 \mathrm{mM} \mathrm{IPTG}$ and $15^{\circ} \mathrm{C}$ was selected as the final condition throughout the study. The Per a 9 protein was purified by Ni column. More than $8.69 \mathrm{mg}$ recombinant Per a 9 was obtained from 1 liter of cell culture. The purity of the purified Per a 9 was identified by SDS-PAGE. It showed a single band with an apparent molecular weight of $40 \mathrm{kDa}$ (Fig. 2B).

Immunoreactivity to IgE. In order to determine the allergenicity of Per a 9, we examined the ability of Per a 9 to bind $\operatorname{IgE}$ in the sera of the patients with American CR allergies using a direct ELISA technique. The sera from all patients apart from patients 4, 6 and 12 exhibited a positive $\operatorname{IgE}$ reactivity to Per a 9. The results revealed that $13 / 16(81.3 \%)$ sera from these patients reacted to Per a 9 (Fig. 3A). The IgE binding activity of Per a 9 in a representative group of 3 patients and 2 healthy 


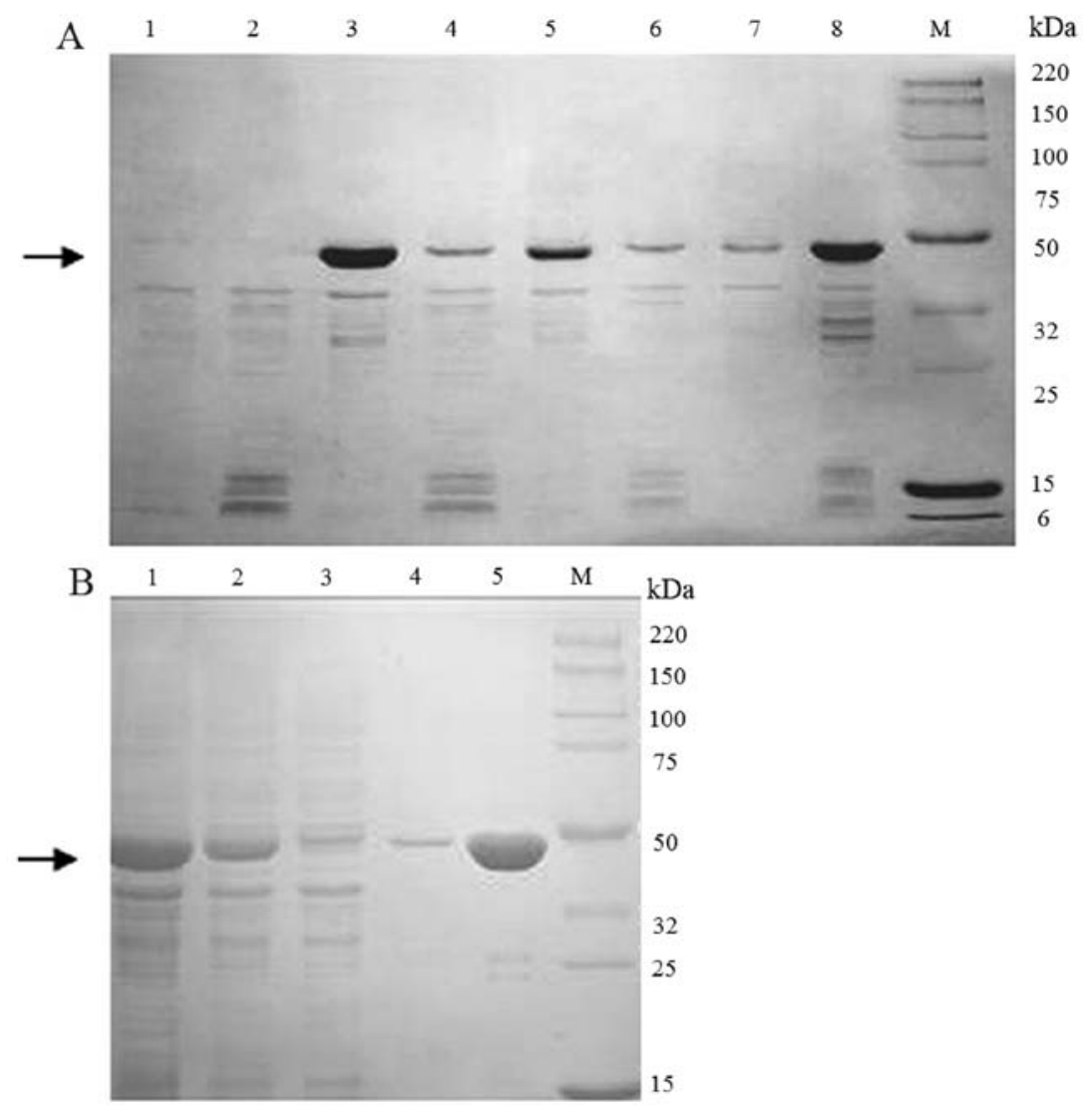

Figure 2. Expression and purification of Per a 9 in E. coli. (A) Per a 9 expressed at 15,25 or $37^{\circ} \mathrm{C}$ was analyzed by sodium dodecyl sulfate-polyacrylamide gel electrophoresis (SDS-PAGE). Lane M, Smart Broad-Range protein standard (Genscript, Nanjing, China); lane 1, the supernatant of un-induced cells; lane 2, the precipitant of un-induced cells; lane 3 , the supernatant of the cells induced at $15^{\circ} \mathrm{C}$; lane 4 , the precipitant of the cells induced at $15^{\circ} \mathrm{C}$; lane 5 , the supernatant of the cells induced at $25^{\circ} \mathrm{C}$; lane 6 , the precipitant of the cells induced at $25^{\circ} \mathrm{C}$; lane 7 , the supernatant of the cells induced at $37^{\circ} \mathrm{C}$; lane 8 , the precipitant of the cells induced at $37^{\circ} \mathrm{C}$. The arrow represents Per a 9 protein. (B) SDS-PAGE analysis of purified Per a 9 expressed in E. coli. Lane M, protein standard; lane 1, total protein after sonication; lane 2, the supernatant after centrifugation; lane 3, flow through; lane 4, washing with $50 \mathrm{mM}$ imidazole; lane 5 , washing with $250 \mathrm{mM}$ imidazole. The arrow represents Per a 9 protein.

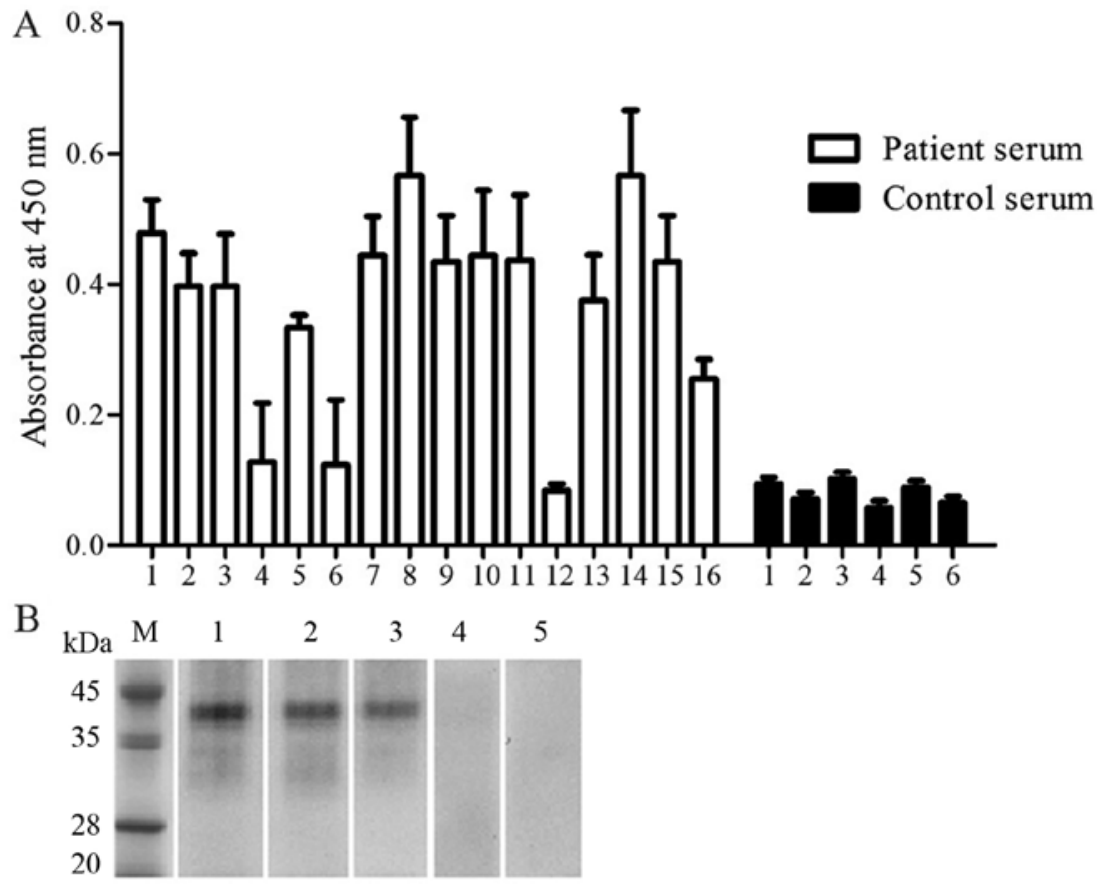

Figure 3. (A) Analysis of specific IgE reactivity of recombinant Per a 9 by direct enzyme-linked immunosorbent assay (ELISA). Sera were collected from patients with American cockroach (CR) allergies and healthy controls. The values are shown as the means \pm SD from triplicate experiments. (B) Western blot analysis of IgE reactivity to Per a 9 sera from the patients with American CR allergy. Lanes 1-3, Per a 9 reacted with the sera from patients 8, 9, 10; lanes 4-5, Per a 9 reacted with sera from control subjects 1 and 2. 
Table I. The predicated secondary structure of Per a 9.

Secondary structural

prediction methods $\alpha$-helices $\beta$-sheets

\begin{tabular}{lll}
\hline PSIPRED & $3-12,25-18,32-39,50-56,73-89,142-156$, & $66-68,210-213,218-223,229-234,260-261$, \\
& $174-183,193-197,240-255,294-303,35-354$ & $266-268,279-286,322-324$ \\
NetSurfP ver1.1 & $2-12,25-28,32-40,50-56,74-89,142-157,175-183$, & $65-69,120-128,209-213,217-223,227-233$, \\
& $193-197,239-256,294-303,333-354$ & $267-269,279-286,307-310,322-326$ \\
PredictProtein & $4-13,25-28,32-39,50-53,78-89,142-157$, & $65-69,167-170,208-213,217-222,232-234$, \\
& $175-183,239-256,294-303,335-355$ & $267-270,279-287,307-311,322-326$ \\
Overall results & $3-12,25-28,32-39,50-56,74-89,142-157$, & $65-69,120-123,210-213,218-223,228-234$, \\
& $175-183,193-197,239-256,294-303,335-354$ & $260-261,280-286,307-310,322-326$
\end{tabular}
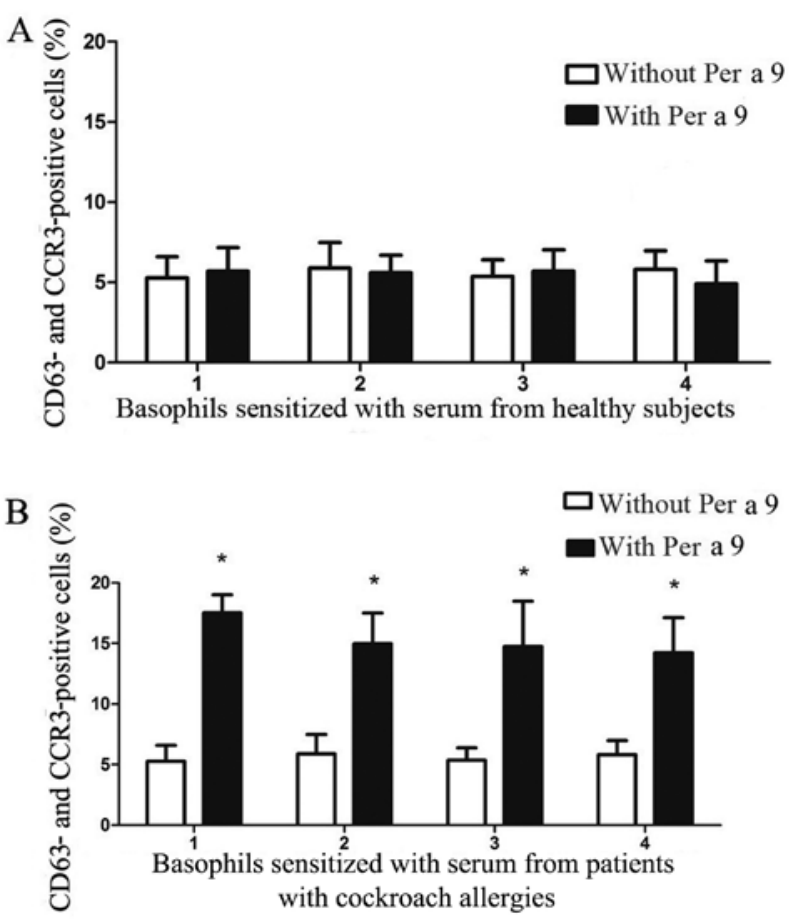

Figure 4. Induction of basophil activation by recombinant Per a 9. After non-specific IgEs on basophils being stripped off, cells from each donor were passively sensitized with sera from 4 different healthy subjects (A) or from 4 different patients with American cockroach (CR) allergies (B), and were then challenged with Per a 9 at $1.0 \mu \mathrm{g} / \mathrm{ml}$. The values are shown as the means \pm SE for the sera from 4 different subjects. ${ }^{*} \mathrm{P}<0.05$ in comparison with the corresponding carrier alone control.

controls were assessed by western blot analysis and the results are illustrated in Fig. 3B.

Per a 9 induces basophil activation. Per a 9 at $1.0 \mu \mathrm{g} / \mathrm{ml}$ induced approximately up to a 4.2-fold increase in the number of CD63 and CCR3 double-positive cells when incubating with passively sensitized basophils from the sera of patients with American CR allergies. Per a 9 had no effect on the basophils sensitized by the sera from HC (Fig. 4).

Sequence retrieval and phylogenetic analysis. Uniprot and tBLASTn were used to search the homologous sequences of Per a 9. As a result, 47 sequences were obtained. In order to determine the relationships between Per a 9 and its homologous sequences, phylogenetic analysis was performed and the evolutionary tree inferred by the ML method is presented in Fig. 5.

Physiochemical analyses, post-translational patterns and motifs. The primary structure of Per a 9 contained 356 amino acids and the molecular weight was 39,735. The theoretical pI was 5.58 and the aliphatic index was 80.56. The GRAVY was -0.413 , which incidated that Per a 9 exhibited a hydrophilic character. The instability index was $31.36(<40)$, indicating that the Per a 9 protein was stable. Per a 9 is an arginine kinase and the results from PROSITE showed that Per a 9 had two obvious characteristic patterns of phosphagen kinase, including PS51509 (phosphagen kinase N-terminal domain profile) and PS51510 (phosphagen kinase C-terminal domain profile). Moreover, PS00112 was contained in PS51510 and consisted of CPTNLGT, which was the active center of phosphagen kinase. The ATP-binding sites were His (185) and Arg (229).

Structural analysis of Per a 9. Secondary structure prediction with PSIPRED identified $11 \alpha$-helices and $8 \beta$-sheets in Per a 9. PredictProtein predicted $10 \alpha$-helices and $9 \beta$-sheets. Alternatively, NetSurfP v1.1 predicted $11 \alpha$-helices and $9 \beta$-sheets. The predicated secondary structure of Per a 9 is presented in Table I.

Homology modeling and validation. The search for the proteins of Per a 9 with known tertiary structure in the PDB yielded Litopenaeus vannamei arginine kinase (PDB Accession no. 4BG4) showing the highest sequence identity (83\% with Per a 9). As a result, the 4BG4 template was used for homology modeling. The homology model that matched the aforementioned structures is shown in Fig. 6A. As indicated by the Ramachandran plot (Fig. 6B), 89.4\% of the residues in the model structure were within the most favored regions, $10 \%$ of the residues were in the additional allowed region, $0.6 \%$ of the residues were in the generously allowed regions and $0 \%$ of the residues were in the disallowed region. As indicated by the ERRAT program, the results (Fig. 6C) revealed that the overall quality factor was 100 , which indicated that the structure had a high resolution. As indicated by the VERIFY_3D program, the results revealed that $99.72 \%$ of the residues had an average 3D (atomic model)-1D (amino acid sequence) score of $>0.2$, which also indicated that 


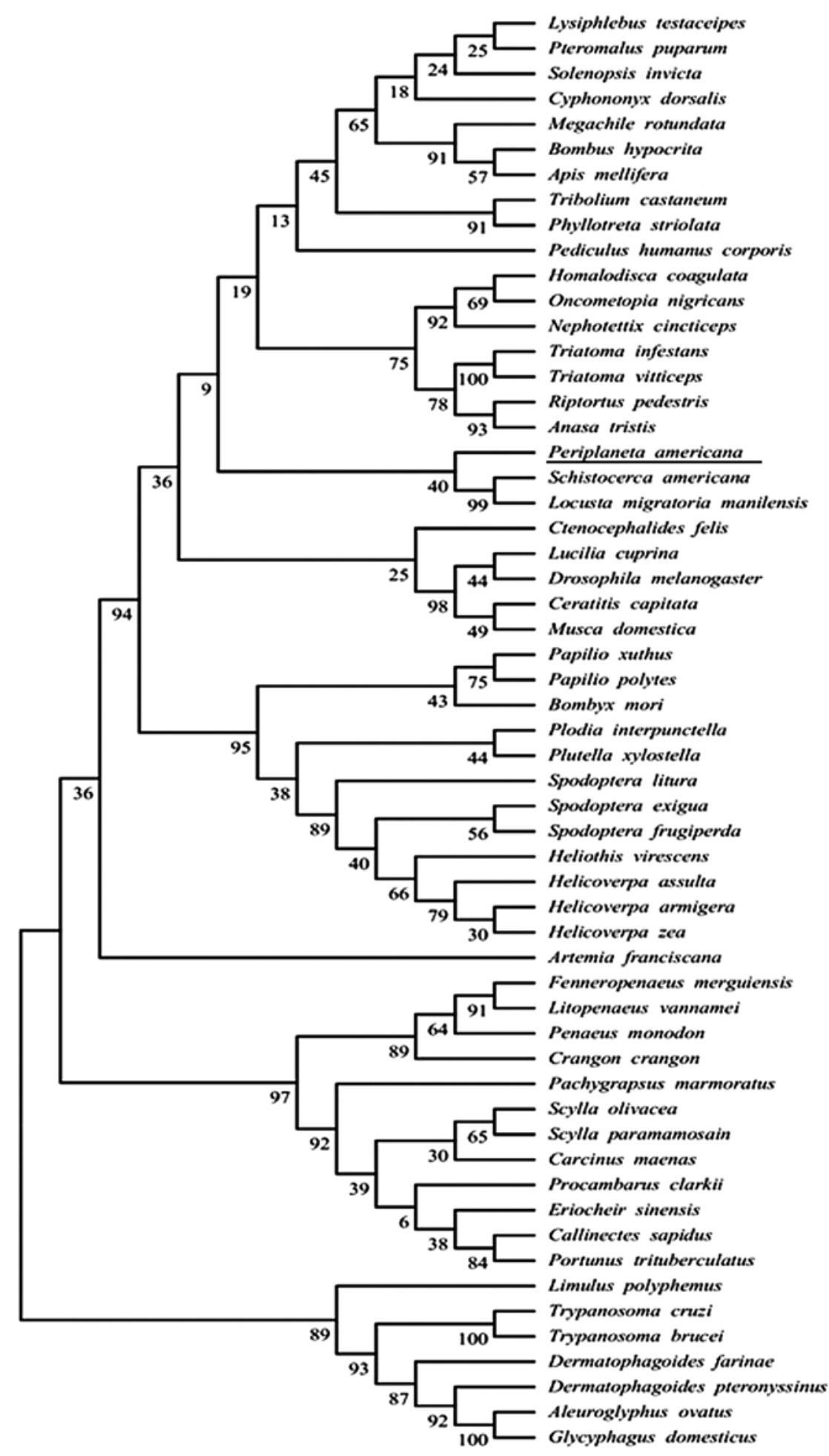

Figure 5. Phylogenetic relationship of Per a 9 allergen amino acid sequence with other homologs.

the structure was good. Based on these validations, it is shown that the homology model was adopted for this study.

$B$ cell epitope prediction. Surface accessibility and fragment flexibility are important features for predicting antigenic epitopes. In addition, the existence of regions with high hydrophobicity also provides strong evidence of epitope identification. The antigenic index directly revealed the epitope forming capacity of the Per a 9 sequence. Based on these sequence properties, the final predicting regions of Per a 9 by DNASTAR were obtained as: 23-31, 38-46, 57-64, 70-72, 91-117, 143-154, 159-165, 174-183, 189-19, 222-227, 292-302, 309-32 and 337-345. The predicted results of the BPAP system were 19-20, 39-46, 58-74, 90-118, 131-136, 145-154, 157-165, 175-176, 275-278, 290-292, 295-299, 309-325 and 338-344. The predicted results of the BepiPred 1.0 server were 11-19, 21-28, 46-55, 115-127, 134-142, 152-158, 176-187, 193-203, 216-222, 238-251, 264-273, 277-293 and 296-308. Furthermore, the final 

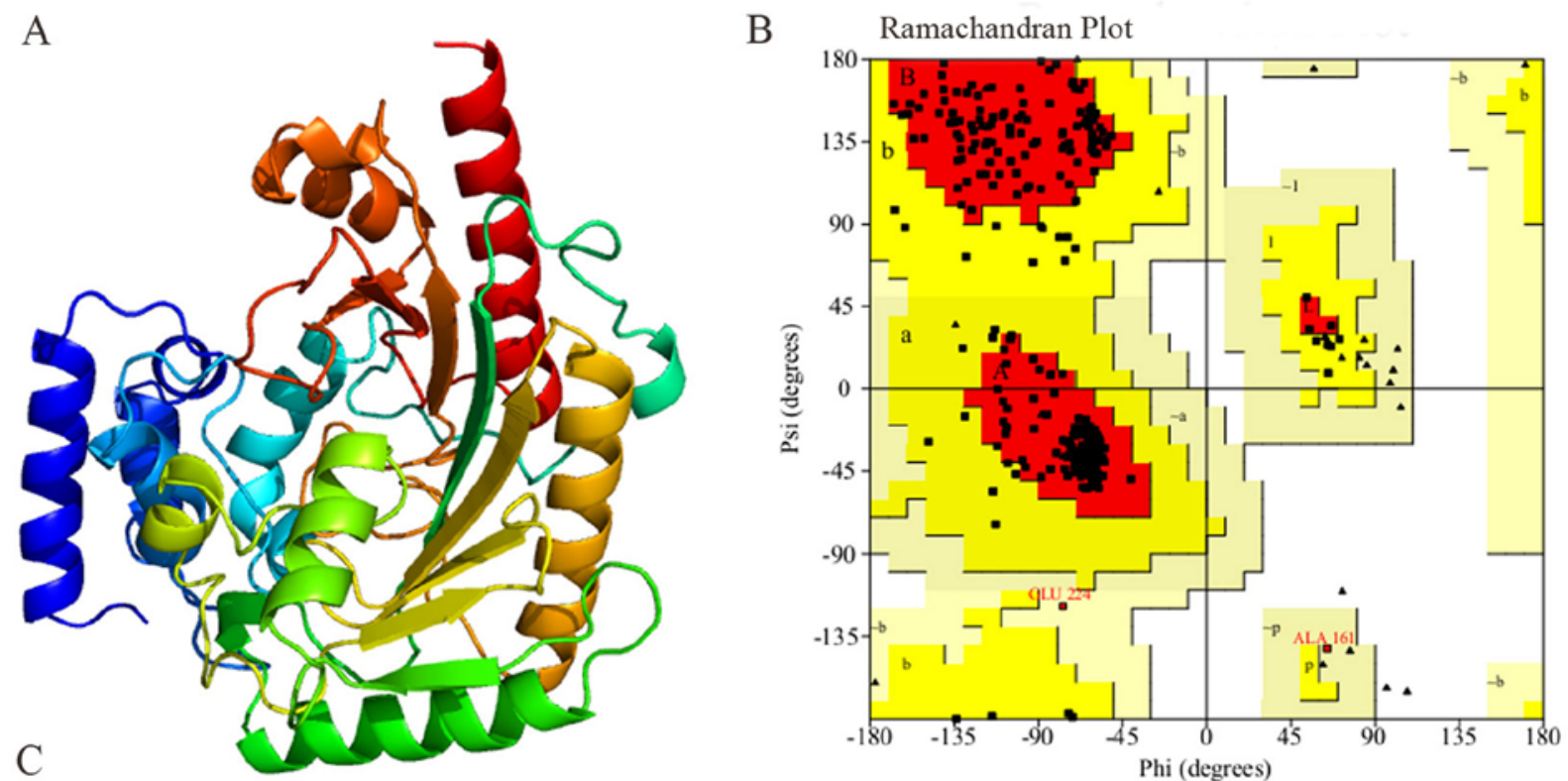

Program: ERRAT2

Chain\#:1

Overall quality factor**: 100.000

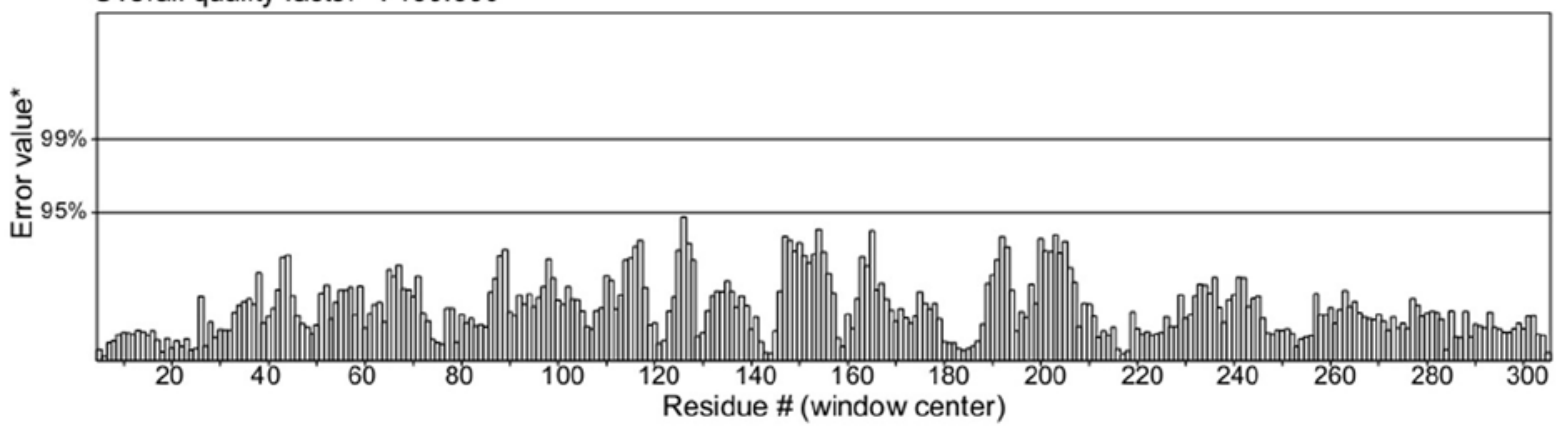

Figure 6. Three-dimensional structure and validation of Per a 9 homology model. (A) Protein structure of Per a 9 homology model. (B) Ramachandran plot of the generated homology model. The residures in most favored regions, additional allowed regions, generously allowed regions and disallowed regions are shown in red, yellow, grey and white in the Ramachandran plot, respectively. (C) Validation of the generated homology model by ERRAT program.
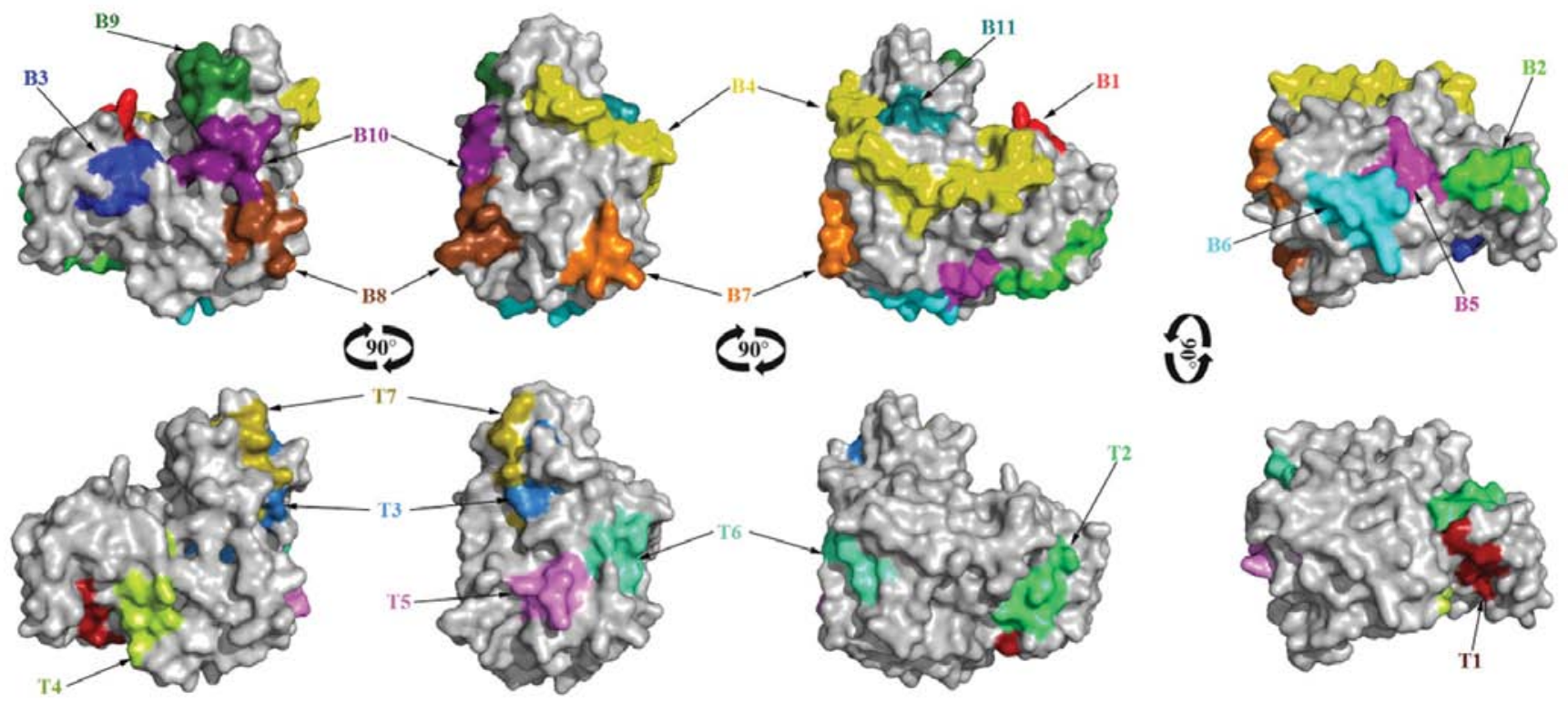

\&

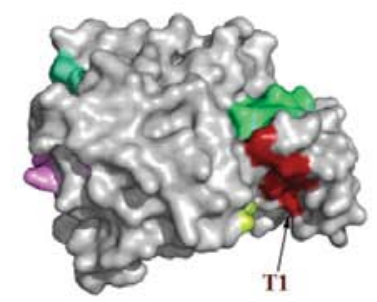

Figure 7. B cell and T cell epitopes superimposition on the surface of Per a 9 allergen structure. B1-B7 are the predicted B cell epitopes; T1-T7 are the predicted $\mathrm{T}$ cell epitopes. 
Table II. The T cell epitope prediction of Per a 9.

HLA types $\quad$ Location of the prediction results

HLA-DR 101

HLA-DR 301

HLA-DR401

HLA-DR501

HLA-DQA10501-DQB10201

HLA-DQA10301-DQB10302

HLA-DQA10501-DQB10301

HLA-DQA10102-DQB10602

The final predicted $\mathrm{T}$ cell epitopes
$7-15,14-22,17-25,23-31,26-34,29-37,35-43,40-48,45-53,46-54,48-56$, 50-58, 67-75, 78-86, 100-108, 117-125, 119-127, 123-131, 128-136, 136-144, 153-161, 156-164, 166-174, 167-175, 168-176, 186-194, 192-200, 194-202, 195-203, 201-209, 210-218, 227-235, 231-239, 238-246, 242-250, 267-275, 268-276, 273-281, 275-283, 277-285, 278-286, 279-287, 282-290, 287-295, 289-297, 290-298, 303-311, 304-312, 305-313, 308-316, 342-350, 348-356,

$68-76,77-85,180-188,211-219,210-218,259-267$

26-34, 29-37, 48-56, 49-57, 119-127, 120-128, 170-178, 194-202, 227-235, 228-236, 231-239, 239-247, 242-250, 245-253, 279-287, 282-290, 283-291, 346-354

8-16, 14-22, 19-27, 22-30, 24-32, 35-43, 118-126, 119-127, 167-175, 185-193, 186-194, 194-202, 195-203, 200-208, 210-218, 239-247, 243-251, 267-275, 278-286, 282-290, 283-291, 284-292, 286-294, 288-296, 289-297, 304-312, 322-330,

$46-54,67-75,65-73,74-82,77-85,186-194,218-226,220-228$

$65-73,71-79,72-80,73-81,79-87,154-162,214-222$

2-10, 7-15, 10-18, 12-20, 13-21, 16-24, 44-52, 46-54, 61-69, 66-74, 71-79, 72-80, 89-97, 115-123, 125-133, 169-177, 194-202, 195-203, 212-220, 234-242, 237-245, 243-251, 274-282, 279-287, 283-291, 292-300, 308-316, 218-226, 242-250

12-20, 45-53, 48-56, 62-70, 72-80, 120-128, 154-162, 189-197, 192-200, 195-203, 214-222, 225-233, 228-236, 274-282, 347-355

46-54, 65-80, 119-127, 194-202, 210-218, 239-250, 279-290 potential B cell epitopes of Per a 9 were selected on the basis of the results of these 3 tools. The ultimate results of the $3 \mathrm{immu}$ noinformatics tools finally predicted 11 peptides $(23-28,39-46$, 58-64, 91-118, 131-136, 145-154, 159-165, 176-183, 290-299, 309-320 and 338-344) and these peptides are shown in Fig. 7.

$T$ cell epitope prediction. For the HLA-DR-based T cell epitope prediction of Per a 9, the final predicting regions of HLA-DR 101, HLA-DR 301, HLA-DR 401 and HLA-DR 501 are shown in Table II and the ultimate results of HLA-DR-based T cell epitope prediction finally predicted 5 peptides (119-127, 194-202, 210-218, 239-250 and 279-290). For HLA-DQ alleles, the final results of HLA-DQA10101-DQB10501, HLA-DQA10301-DQB10302, HLA-DQA10401-DQB10402, and HLA-DQA10102-DQB10602 are also shown in Table II and the ultimate results of these 4 methods finally predicted 2 peptides, 46-54 and 65-80. As a result, Per a 9 was predicted to have $7 \mathrm{~T}$ cell epitope sequences, 46-54, 65-80, 119-127, 194-202, 210-218, 239-250 and 279-290 as shown in Fig. 7.

\section{Discussion}

To better understand the Per a 9-mediated CR allergies and with an aim to improve the diagnosis and treatment of CR allergies, we prepared biologically active and highly pure American CR allergen Per a 9 in relatively large amount in the present study. Per a 9, an arginine kinase, has been reported to be purified from American CR extract by monoclonal antibody based-affinity chromatography (12), but the quantity obtained was limited. Since monoclonal antibody based-affinity chromatography is very costly and tedious, it is not suitable for the production of large amounts of target protein. We therefore prepared recombinant Per a 9 using $E$. coli expression systems in the present study. We found that as little as 1 liter of $E$. coli was able to produce $8.69 \mathrm{mg}$ of highly pure recombinant Per a 9, which is sufficient for the functional analysis of Per a 9.

It is well known that the advantages of the prokaryotic (E. coli) system are easy handling and the expression of high-quantity of target proteins (45); however, one of the disadvantages is that insoluble, inactive inclusion bodies are frequently formed, which means that protein needs to be reconstituted in vitro following solubilization under denaturing conditions to achieve biological activity. Moreover, the application of non-glycosylated recombinant allergens in allergy diagnosis frequently yields false results, as the recombinant allergens lack glycan structures of their natural counterparts, which IgE supposedly react with (46). It has been discovered that Per a 9 contains 356 amino acids with a calculated molecular weight of $39.74 \mathrm{kDa}$, and Per a 9 purified from American CR extract by monoclonal antibody based-affinity chromatography exhibits a molecular weight of $40.57 \mathrm{kDa}$ (12), indicating that few glycan structures exist in Per a 9 protein. In the present study, Per a 9 expressed in the ArcticExpress ${ }^{\mathrm{TM}}$ (DE3) RP host strain was soluble with a molecular weight of $40 \mathrm{kDa}$, without any reconstitution process, indicating that Per a 9 obtained herein should have its immunological and biological functions.

Our results showed that $81.3 \%$ of the sera from patients with CR allergies reacted to Per a 9, proving that Per a 9 is a major allergen of the American CR. A similar finding has been previously reported in the Thai population (12). The 
basophil activation test we employed herein is a more advanced technique for the determination of the allerginicity of a given compound. We confirmed that Per a 9 is an active allergen of $\mathrm{CR}$ as it was able to activate basophils which were sensitized by CR allergy sera. The availability of recombinant allergens has increased our understanding of IgE-mediated allergies and may improve the diagnosis and treatment of these diseases (47). In our case, recombinant Per a 9 should be a useful tool for the functional and clinical analysis of this allergen.

Allergen-specific IgE is the key molecule for the development of allergic symptoms. The synthesis of IgE requires a B cell to undergo class switch recombination in close contact with allergen-specific T helper 2 cells (Th2) (48). In a previous study, overlapping synthetic peptides were frequently used to validate the IgE-binding capacity. Although this method decreases the possibility of missed epitopes, it needs to synthesize lots of peptides and is very costly and time-consuming (49). In silico prediction has already become a familiar and useful tool for selecting epitopes from immunologically relevant proteins, which can save the expense of synthetic peptides and the working time (50). A previous study demonstrated that the use of the bioinformatics approach to predict B cell epitopes correlated well with the experimental approach (51). Many algorithms have been developed to predict $B$ cell epitopes on a protein sequence based on the propensity values of amino acid properties of hydrophilicity, antigenicity, segmental mobility, flexibility and accessibility (48). In the present study, we predicted the B cell linear epitopes of Per a 9 allergens by 3 sequence based tools (the DNASTAR protean system, BPAP and the BepiPred 1.0 server) and predicted 11 peptides (23-28, 39-46, 58-64, 91-118, 131-136, 145-154, 159-165, 176-183, 290-299, 309-320 and 338-344) as potential B cell linear epitopes. Over the past several years, some algorithms have substantially improved their accuracy to predict $\mathrm{T}$ cell epitopes. However, most algorithms have targeted HLA-DR molecules, but not HLA-DP and HLA-DQ molecules, even though they are important for antigen presentation. NetMHCpan-2.0 has recently been evaluated to have a per-allele mean accuracy of 0.854 (1.0 being $100 \%$ accurate, and 0.5 of no significance) (52). In another study, the per-allele mean accuracy of NN-align was 0.882 (53). In this study, Net-MHCIIpan-2.0 and NetMHCII-2.2 were used to predict the core 9 -mer T cell epitopes in the Per a 9 allergens and predicted 5 potential T cell epitope sequences, 119-127, 194-202, 210-218, 239-250 and 279-290.

Allergen-specific immunotherapy (SIT) is the only treatment able to cure allergic diseases. Numerous studies have shown that crude allergen extracts currently used in SIT are clinically effective (54-56); a high allergen dose is more effective, although the potential risk of severe acute side-effects is a limiting factor. Attenuated allergenic molecules, i.e., hypoallergens or synthetic peptide fragments have been used as high-dose and safer alternatives to conventional extract-based SIT (57). Vaccination with a combination of small peptides that together extend across the entire native allergenic protein theoretically could preserve $\mathrm{T}$ cell activation, while avoiding IgE-based immune responses. IgE recognizes conformational epitopes of larger peptides (B cell epitopes) and proteins, while $\mathrm{T}$ cell receptors recognize small linear peptides of 8 to 10 amino acids ( $\mathrm{T}$ cell epitope). By immunizing with small peptides, $\mathrm{T}$ cell activation could occur, while IgE binding would be lost (58-60).
In conclusion, in the present study, we prepared recombinant Per a 9 allergens using a prokaryotic expression system. We confirm that Per a 9 is a major allergen of the American $\mathrm{CR}$, which can activate basophils in vitro. Recombinant Per a 9 may prove to be a useful tool for studying and understanding the role of Per a 9 in CR allergies. We also predicted B and T cell epitopes of the Per a 9 allergen, the major allergen in the American CR, using the in silico method, which can be used to benefit allergen immunotherapies and reduce the frequency of allergic reactions. However, their accuracies need to be confirmed in the further experiments.

\section{Acknowledgements}

This study was sponsored by grants from the Special Fund for Forestry-scientific Research in the Public Interest (no. 201304103); the National Natural Science Foundation of China (nos. 81571568, 31340073 and 81273274); Jiangsu Province's Key Provincial Talents Program (no. RC201170); the Priority Academic Program Development of Jiangsu Higher Education Institutions (PAPD); National 'Twelfth Five-Year' Plan for Science and Technology Support Project (no. 2014BAI07B02); the Innovation team project of Education Department of Liaoning Province (no. LT2013017); the higher Education Climb scholars Program of Liaoning Province, China (no. LJ2013222); and the Liaoning Province Translational Medicine Research Center for Allergy (no. LK2013041).

\section{References}

1. Bernton HS and Brown H: Insect allergy preliminary studies of the cockroach. J Allergy 35: 506-513, 1964.

2. Arruda LK, Vailes LD, Ferriani VPL, Santos AB, Pomés A and Chapman MD: Cockroach allergens and asthma. J Allergy Clin Immunol 107: 419-428, 2001

3. Sun BQ, Lai XX, Gjesing B, Spangfort MD and Zhong NS: Prevalence of sensitivity to cockroach allergens and IgE crossreactivity between cockroach and house dust mite allergens in Chinese patients with allergic rhinitis and asthma. Chin Med J (Engl) 123: 3540-3544, 2010.

4. Thangam Sudha V, Arora N, Sridhara S, Gaur SN and Singh BP: Biopotency and identification of allergenic proteins in Periplaneta americana extract for clinical applications. Biologicals 35: 131-137, 2007.

5. He S, Zhang Z, Zhang H, Wei J, Yang L, Yang H, Sun W, Zeng $X$ and Yang P: Analysis of properties and proinflammatory functions of cockroach allergens Per a 1.01s. Scand J Immunol 74: 288-295, 2011.

6. Wu HQ, Liu ZG, Ran PX, Zhou ZW and Gao B: Expression, purification, and immunological characterization of $\mathrm{Cr}$ PI. Protein Pept Lett 14: 881-885, 2007.

7. Mindykowski B, Jaenicke E, Tenzer S, Cirak S, Schweikardt T, Schild H and Decker H: Cockroach allergens Per a 3 are oligomers. Dev Comp Immunol 34: 722-733, 2010.

8. Tan YW, Chan SL, Ong TC, Yit Y, Tiong YS, Chew FT, Sivaraman J and Mok YK: Structures of two major allergens, Bla g 4 and Per a 4, from cockroaches and their IgE binding epitopes. J Biol Chem 284: 3148-3157, 2009.

9. Wei JF, Yang H, Li D, Gao P and He S: Preparation and identification of Per a 5 as a novel American cockroach allergen. Mediators Inflamm 591468: 2014, 2014.

10. Chen H, Yang HW, Wei JF, and Tao AL: In silico prediction of the T-cell and IgE-binding epitopes of Per a 6 and Bla g 6 allergens in cockroaches. Mol Med Rep 10: 2130-2136, 2014.

11. Yang H, Kong X, Wei J, Liu C, Song W, Zhang W, Wei W and He S: Cockroach allergen Per a 7 down-regulates expression of Toll-like receptor 9 and IL-12 release from P815 cells through PI3K and MAPK signaling pathways. Cell Physiol Biochem 29: 561-570, 2012. 
12. Sookrung N, Chaicumpa W, Tungtrongchitr A, Vichyanond $P$, Bunnag C, Ramasoota P, Tongtawe P, Sakolvaree Y and Tapchaisri P: Periplaneta americana arginine kinase as a major cockroach allergen among Thai patients with major cockroach allergies. Environ Health Perspect 114: 875-880, 2006.

13. Sudha VT, Arora N, Gaur SN, Pasha S and Singh BP: Identification of a serine protease as a major allergen (Per a 10) of Periplaneta americana. Allergy 63: 768-776, 2008.

14. Kang BC, Johnson J, Morgan C and Chang JL: The role of immunotherapy in cockroach asthma. J Asthma 25: 205-218, 1988

15. Srivastava D, Gaur SN, Arora N and Singh BP: Clinicoimmunological changes post-immunotherapy with Periplaneta americana. Eur J Clin Invest 41: 879-888, 2011.

16. Sharma V, Singh BP, Gaur SN, Pasha S and Arora N Bioinformatics and immunologic investigation on $\mathrm{B}$ and $\mathrm{T}$ cell epitopes of Cur 13 , a major allergen of Curvularia lunata. J Proteome Res 8: 2650-2655, 2009.

17. Wang HW, Lin YC, Pai TW and Chang HT: Prediction of B-cell linear epitopes with a combination of support vector machine classification and amino acid propensity identification. J Biomed Biotechnol 2011: 432830, 2011.

18. Nielsen M, Lund O, Buus S and Lundegaard C: MHC class II epitope predictive algorithms. Immunology 130: 319-328, 2010.

19. An S, Chen L, Wei JF, Yang X, Ma D, Xu X, Xu X, He S, $\mathrm{Lu} J$ and Lai R: Purification and characterization of two new allergens from the venom of Vespa magnifica. PLoS One 7: e31920, 2012.

20. An S, Ma D, Wei JF, Yang X, Yang HW, Yang H, Xu X, He S and Lai R: A novel allergen Tab y 1 with inhibitory activity of platelet aggregation from salivary glands of horseflies. Allergy 66: $1420-1427,2011$.

21. Sanz ML, Gamboa PM, Antépara I, Uasuf C, Vila L, Garcia-Avilés C, Chazot M and De Weck AL: Flow cytometric basophil activation test by detection of CD63 expression in patients with immediate-type reactions to betalactam antibiotics. Clin Exp Allergy 32: 277-286, 2002.

22. Sainte-Laudy J, Vallon C and Guérin JC: Analysis of membrane expression of the CD63 human basophil activation marker. Applications to allergologic diagnosis. Allerg Immunol (Paris) 26: 211-214, 1994 (In French).

23. Liu F, Wei XL, Li H, Wei JF, Wang YQ and Gong XJ: Molecular evolution of the vertebrate FK506 binding protein 25 . Int J Genomics 2014: 402603, 2014

24. Yang L, Luo $\mathrm{Y}$ and Wei J: Integrative genomic analyses on Ikaros and its expression related to solid cancer prognosis. Oncol Rep 24: 571-577, 2010.

25. Yang L, Luo Y, Wei J and He S: Integrative genomic analyses on IL28RA, the common receptor of interferon- $\lambda 1,-\lambda 2$ and $-\lambda 3$. Int J Mol Med 25: 807-812, 2010.

26. Yang L, Wei J and He S: Integrative genomic analyses on interferon- $\lambda \mathrm{s}$ and their roles in cancer prediction. Int $\mathbf{J}$ Mol Med 25: 299-304, 2010.

27. Yu H, Yuan J, Xiao C and Qin Y: Integrative genomic analyses of recepteur d'origine nantais and its prognostic value in cancer. Int J Mol Med 31: 1248-1254, 2013.

28. Wang M, Wei X, Shi L, Chen B, Zhao G and Yang H: Integrative genomic analyses of the histamine $\mathrm{H} 1$ receptor and its role in cancer prediction. Int J Mol Med 33: 1019-1026, 2014

29. Wang B, Chen K, Xu W, Chen D, Tang W and Xia TS: Integrative genomic analyses of secreted protein acidic and rich in cysteine and its role in cancer prediction. Mol Med Rep 10: 1461-1468, 2014.

30. Wang B, Xu W, Tan M, Xiao Y, Yang H and Xia TS: Integrative genomic analyses of a novel cytokine, interleukin-34 and its potential role in cancer prediction. Int J Mol Med 35: 92-102, 2015

31. Jin M, Yang HW, Tao AL and Wei JF: Evolution of the proteaseactivated receptor family in vertebrates. Int J Mol Med 37: 593-602, 2016.

32. Ding Z, Yang HW, Xia TS, Wang B and Ding Q: Integrative genomic analyses of the RNA-binding protein, RNPC1, and its potential role in cancer prediction. Int J Mol Med 36: 473-484, 2015.

33. Li X, Yang HW, Chen H, Wu J, Liu Y and Wei JF: In silico prediction of $\mathrm{T}$ and $\mathrm{B}$ cell epitopes of Der $\mathrm{f} 25$ in dermatophagoides farinae. Int J Genomics 2014: 483905, 2014.

34. Sigrist CJE, de Castro L, Cerutti BA, Cuche N, Hulo A, Bridge L, Bougueleret L and Xenarios I: New and continuing developments at PROSITE. Nucleic Acids Res 41(Database issue): D344-D347, 2013.

35. McGuffin LJ, Bryson K and Jones DT: The PSIPRED protein structure prediction server. Bioinformatics 16: 404-405, 2000.
36. Petersen B, Petersen TN, Andersen P, Nielsen M and Lundegaard C A generic method for assignment of reliability scores applied to solvent accessibility predictions. BMC Struct Biol 9: 51, 2009.

37. Laskowski RA, MacArthur MW and Thornton JM: Validation of protein models derived from experiment. Curr Opin Struct Biol 8: 631-639, 1998.

38. Maganti L, Manoharan P and Ghoshal N: Probing the structure of Leishmania donovani chagasi DHFR-TS: comparative protein modeling and protein-ligand interaction studies. J Mol Model 16: 1539-1547, 2010.

39. Burland TG: DNASTAR's Lasergene sequence analysis software. Methods Mol Biol 132: 71-91, 2000.

40. Larsen JE, Lund $\mathrm{O}$ and Nielsen $\mathrm{M}$ : Improved method for predicting linear B-cell epitopes. Immunome Res 2: 2, 2006.

41. Yang X and Yu X: An introduction to epitope prediction methods and software. Rev Med Virol 19: 77-96, 2009.

42. Zheng LN, Lin H, Pawar R, Li ZX and Li MH: Mapping IgE binding epitopes of major shrimp (Penaeus monodon) allergen with immunoinformatics tools. Food Chem Toxicol 49: 2954-2960, 2011

43. Karosiene E, Rasmussen M, Blicher T, Lund O, Buus S and Nielsen M: NetMHCIIpan-3.0, a common pan-specific MHC class II prediction method including all three human MHC class II isotypes, HLA-DR, HLA-DP and HLA-DQ. Immunogenetics 65: 711-724, 2013.

44. Nielsen $\mathrm{M}$ and Lund $\mathrm{O}$ : $\mathrm{NN}$-align. An artificial neural networkbased alignment algorithm for MHC class II peptide binding prediction. BMC Bioinformatics 10: 296, 2009.

45. Wallner M, Gruber P, Radauer C, Maderegger B, Susani M, Hoffmann-Sommergruber K and Ferreira F: Lab scale and medium scale production of recombinant allergens in Escherichia coli. Methods 32: 219-226, 2004.

46. Malandain H: IgE-reactive carbohydrate epitopes - classification, cross-reactivity, and clinical impact. Eur Ann Allergy Clin Immunol 37: 122-128, 2005.

47. Schmidt M and Hoffman DR: Expression systems for production of recombinant allergens. Int Arch Allergy Immunol 128: 264-270, 2002

48. Pomés A: Relevant B cell epitopes in allergic disease. Int Arch Allergy Immunol 152: 1-11, 2010.

49. Lin J, Bardina L, Shreffler WG, Andreae DA, Ge Y, Wang J, Bruni FM, Fu Z, Han Y and Sampson HA: Development of a novel peptide microarray for large-scale epitope mapping of food allergens. J Allergy Clin Immunol 124: 315-322. e313, 2009.

50. Li GF, Wang Y, Zhang ZS, Wang XJ, Ji MJ, Zhu X, Liu F, Cai XP, Wu HW and Wu GL: Identification of immunodominant Th1-type T cell epitopes from Schistosoma japonicum $28 \mathrm{kDa}$ glutathione-S-transferase, a vaccine candidate. Acta Biochim Biophys Sin (Shanghai) 37: 751-758, 2005.

51. Nair S, Kukreja N, Singh BP and Arora N: Identification of B cell epitopes of alcohol dehydrogenase allergen of Curvularia lunata. PLoS One 6: e20020, 2011.

52. Nielsen M, Justesen S, Lund O, Lundegaard C and Buus S: NetMHCIIpan-2.0 - Improved pan-specific HLA-DR predictions using a novel concurrent alignment and weight optimization training procedure. Immunome Res 6: 9, 2010.

53. Wang P, Sidney J, Kim Y, Sette A, Lund O, Nielsen $M$ and Peters B: Peptide binding predictions for HLA DR, DP and DQ molecules. BMC Bioinformatics 11: 568, 2010.

54. Akdis CA and Akdis M: Advances in allergen immunotherapy: aiming for complete tolerance to allergens. Sci Transl Med 7: 280 ps6, 2015.

55. Soyka MB, van de Veen W, Holzmann D, Akdis M and Akdis CA Scientific foundations of allergen-specific immunotherapy for allergic disease. Chest 146: 1347-1357, 2014.

56. Jutel $\mathrm{M}$ and Akdis CA: Novel immunotherapy vaccine development. Curr Opin Allergy Clin Immunol 14: 557-563, 2014.

57. Passalacqua G and Canonica GW: Specific immunotherapy in asthma: Efficacy and safety. Clin Exp Allergy 41: 1247-1255, 2011.

58. Larché M: T cell epitope-based allergy vaccines. Curr Top Microbiol Immunol 352: 107-119, 2011.

59. Pascal M, Konstantinou GN, Masilamani M, Lieberman J and Sampson HA: In silico prediction of Ara h $2 \mathrm{~T}$ cell epitopes in peanut-allergic children. Clin Exp Allergy 43: 116-127, 2013.

60. Nilsson OB, Adedoyin J, Rhyner C, Neimert-Andersson T, Grundström J, Berndt KD, Crameri R and Grönlund H: In vitro evolution of allergy vaccine candidates, with maintained structure, but reduced B cell and T cell activation capacity. PLoS One 6: e24558, 2011. 